\title{
Landscape video mosaic from a mesophotic coral reef
}

Received: 20 July 2009/Accepted: 17 August 2009/Published online: 18 September 2009

(C) Springer-Verlag 2009

Landscape video mosaics (Lirman et al. 2007) were acquired at four sites in the Hind Bank Marine Conservation District, US Virgin Islands (Smith et al. In press), one of which is shown here (Fig. 1). This mosaic covers $31 \mathrm{~m}^{2}$ with a resolution of $1.8 \mathrm{~mm} /$ pixel. Live stony coral cover, estimated from 400 random points on the mosaic, was high (42.5\%). The community was dominated by plating or encrusting forms of colonies of the genus Montastraea. Other coral genera identified from the video at lower abundance included Agaricia, Colpophyllia, Helioseris, Mycetophyllia, and Porites.

Dive time and diver training were not obstacles to video acquisition for landscape mosaics, which in this case took only 25 min per mosaic by a diver who had only one practice acquisition. Processing each mosaic took about $1 \mathrm{~h}$ of analyst time and $24 \mathrm{~h}$ of computer time. The ease of data acquisition, ability to use off-the-shelf hardware (i.e., a video camera and possibly lights), and potential suite of indicators (e.g., benthic cover, coral sizes, disease prevalence, and bleaching) that can be obtained from the images suggest that landscape mosaics could be applied widely for surveys of mesophotic coral ecosystems.
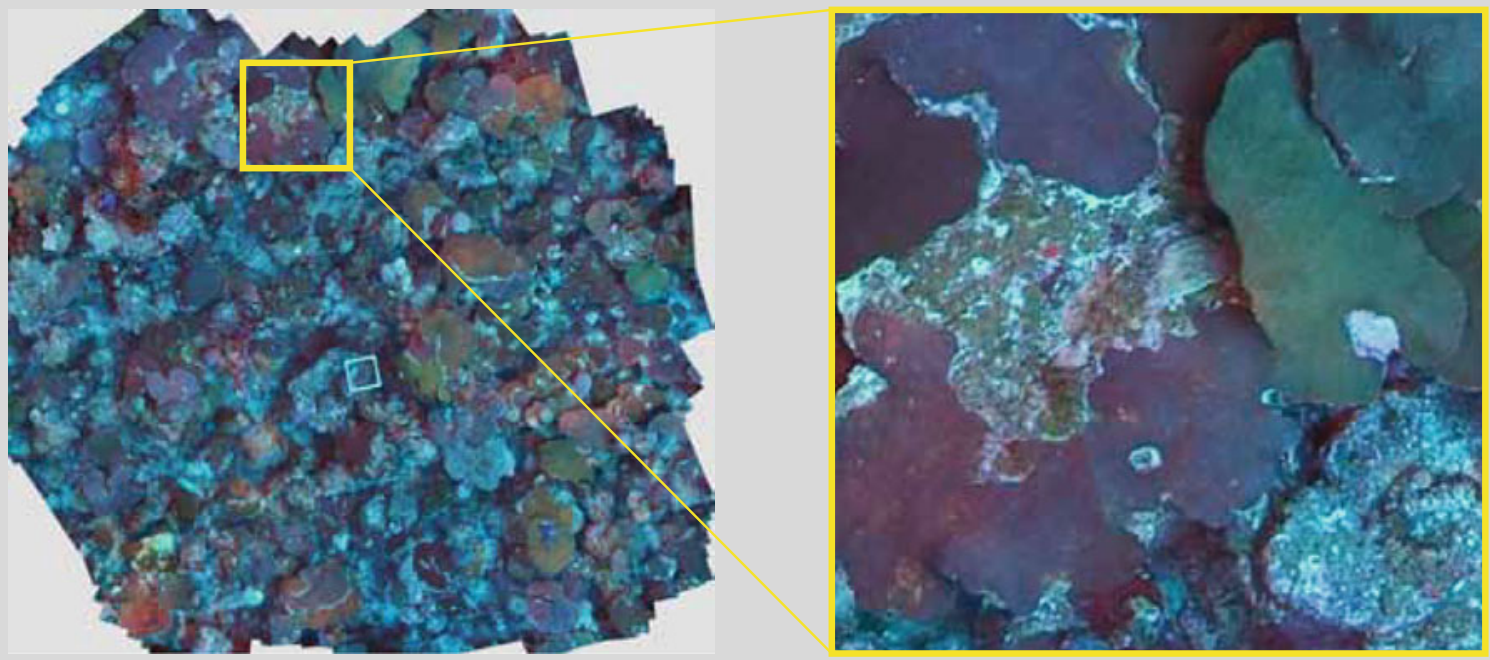

Fig. 1 Landscape video mosaic showing the flattened, platy coral morphology common at mesophotic depths $\left(18^{\circ} 11.8083^{\prime} \mathrm{N}, 65^{\circ} 04.7451^{\prime} \mathrm{W}, 38.5 \mathrm{~m}\right.$ depth). Inset highlights evidence of old partial mortality. The use of supplementary illumination resulted in red highlights visible on the parts of the plot closest to the diver. Mosaic was created by processing 3,811 video frames, from which 211 were used for rendering. Quadrat is $25 \times 25 \mathrm{~cm}$

Acknowledgments Strategic Environmental Defense Research Program (SI-1333 to R.P.R.), Caribbean Fishery Management Council (T.B.S.), and Spanish Ministry of Education and Science (N.G.) provided funding. J. Blondeau, J. Calnan, E. Kadison, and R. Nemeth assisted in the field.

References

Lirman D, Gracias NR, Gintert BE, Gleason ACR, Reid RP, Negahdaripour S, Kramer P (2007) Development and application of a video-mosaic survey technology to document the status of coral reef communities. Environ Monit Assess 125:59-73

Smith TB, Blondeau J, Nemeth RS, Pittman SJ, Calnan JM, Kadison E, Gass J (In press) Benthic structure and cryptic mortality in a Caribbean mesophotic coral reef bank system, the Hind Bank Marine Conservation District, U.S. Virgin Islands. Coral Reefs

A. C. R. Gleason $(\bowtie) \cdot$ D. Lirman - B. E. Gintert · M. C. Dick · R. P. Reid

University of Miami, 4600 Rickenbacker Cswy, Miami, FL 33149, USA

e-mail: art.gleason@miami.edu

URL: http://www.rsmas.miami.edu/groups/reidlab

N. Gracias

University of Girona, Avda. Lluis Santalo S/N, 17071 Girona, Spain

T. B. Smith

University of the Virgin Islands, \#2 John Brewer's Bay, St. Thomas 00802, US Virgin Islands

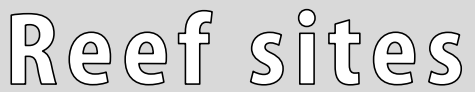

Coral Reefs (2010) 29:253

DOI $10.1007 / \mathrm{s} 00338-009-0544-2$ 